\title{
A systematic review of anti-thrombotic therapy in epistaxis*
}

\author{
K.M. Musgrave ${ }^{1,2}$ and J. Powell1,3 \\ ' Institute of Cellular Medicine, Newcastle University, Newcastle upon Tyne, United Kingdom \\ 2 Department of Haematology, Freeman Hospital, Newcastle Upon Tyne, United Kingdom \\ ${ }^{3}$ Department of Otolaryngology-Head and Neck Surgery, Freeman Hospital, Newcastle Upon Tyne, United Kingdom
}

Rhinology 54: 292-301, 2016

DOI:10.4193/Rhino16.040

*Received for publication:

February 5, 2016

Accepted: May 17, 2016

\begin{abstract}
There is limited guidance available to clinicians regarding the management of antithrombotic therapy during epistaxis, whilst there has been an increase in the use of anticoagulation and antiplatelet therapy. In addition, the introduction of direct oral anticoagulants (DOACs), such as dabigatran and rivaroxaban, over the last decade has significantly increased the complexity of managing the anticoagulated epistaxis patient. We undertook a systemic literature review investigating potential management strategies for each class of anti-thrombotic therapy during epistaxis. A PubMED and Cochrane Library search was performed on 10/03/16 using, but not limited to, the search terms 'epistaxis,',nosebleed,',nose bleeding,',nasal haemorrhage,',nasal bleeding' AND each of the following search terms:'antithrombotic,'anticoagulant,'antiplatelet,'aspirin,',clopidogrel,'warfarin', 'dabigatran', 'rivaroxaban', 'apixaban' and 'tranexamic acid.' This yielded 3815 results, of which 29 were considered relevant. Other sources such as national and international guidelines related to the management of anti- thrombotics were also utilised. We present the findings related to the management of each class of anti-thrombotic therapy during epistaxis. Overall we found a lack of evidence regarding this topic and further high quality research is needed. This is an area growing in complexity and the support of colleagues in Haematology and Cardiology is increasingly important.
\end{abstract}

Key words: epistaxis, anticoagulants, platelet aggregation inhibitors, anticoagulants, tranexamic acid

\section{Introduction}

Epistaxis is a common disorder accounting for $33 \%$ of all Otolaryngology emergency admissions ${ }^{(1)}$. In the United Kingdom 20,000 emergency admissions were due to epistaxis in 20142015, resulting in 39,000 hospital bed days [(http://www.hscic. gov.uk/ accessed 21/01/16)]. The majority of admissions are in older adults, with a median age at admission of 70 years ${ }^{(1)}$.

Anti-thrombotic therapy is used in up to $60 \%$ of admissions for epistaxis; it is associated with longer hospitals stays and higher rates of readmission ${ }^{(2-6)}$. In addition, the introduction of direct oral anticoagulants (DOACs), such as dabigatran and rivaroxaban, over the last decade, has significantly increased the complexity of managing the anticoagulated epistaxis patient.

Anti-thrombotic use is increasing, particularly in the older age groups ${ }^{(3,7-9)}$. There is a scarcity of guidance available for the management of antithrombotic therapy during epistaxis, especially related to newer anticoagulants ${ }^{(2,10,11)}$. We performed a systematic literature review of the current evidence, with a focus on potential management strategies for each class of antithrombotic therapy.

\section{Materials and methods}

A comprehensive literature search was performed using PubMED and the Cochrane Library on the 10th March 2016. A keyword search was undertaken using the search terms 'epistaxis', 'nosebleed,' 'nose bleeding,' 'nasal haemorrhage,',nasal bleeding' AND each of the following search terms:'antithrombotic,'anticoagulant,',antiplatelet', 'aspirin', 'Ecotrin,' 'acetylsalicyclic acid', 'clopidogrel,' 'Plavix,', warfarin', 'Coumadin', 'coumarin', 'vitamin K antagonists,' 'dabigatran,' 'Pradaxa,',rivaroxaban', 'Xarelto','apixaban', 'Eliquis' and 'tranexamic acid'. Search results were limited to English language articles, those published in a peer-reviewed journal since 1985 and those related to the care of individuals greater than 16 years of age. Single case reports and personal opinion were excluded. Studies were chosen that were relevant to the question: 'What evidence-based management strategies 
exist for antithrombotic agents during an episode of epistaxis?'

\section{Results}

The search yielded 3815 results, of which 29 were considered relevant (Figure 1). There were 5 randomised controlled trials (RCTs), 9 prospective observational studies, 7 retrospective studies, 8 literature reviews and 2 systemic reviews. All are discussed below. There was very little evidence relating to anticoagulant management in epistaxis and no study specifically addressing the management of the newer oral anticoagulants. Given this lack of directly related evidence, the below guidance is also informed by international guidelines on anticoagulants and bleeding and studies from other bleeding conditions.

\section{Initial assessment}

\section{Risk assessment of individuals}

There is no universally accepted grading system for the severity of epistaxis. For the purposes of this review the authors have used the following grouping of epistaxis severity, based on the general groupings in the reviewed literature (Table 1).

During the initial assessment of an epistaxis patient it is vital to determine the reason an individual is taking anti-thrombotic therapy and to perform a risk assessment prior to modification of a patient's anti-thrombotic regime. Currently, there is insufficient evidence to guide this risk assessment during an episode of epistaxis.

Those at highest risk of complications due to stopping or reducing anti-thrombotic agents include: recent cardiac stent insertion, new venous thromboembolism and metallic heart valves.

The British Committee for Standards in Haematology guidelines
Table 1. Proposed groupings of bleed severity.

\begin{tabular}{|ll|}
\hline Severity & Definition \\
\hline Mild & $\begin{array}{l}\text { Does not require admission and could be resolved by } \\
\text { simple measures, including cautery. }\end{array}$ \\
Moderate & $\begin{array}{l}\text { Requires admission due to bleeding severity or lack of } \\
\text { control with simple measures. No associated evidence of } \\
\text { shock or immediate threat to life. }\end{array}$ \\
Severe & Evidence of shock or imminent life-threatening bleeding. \\
\hline
\end{tabular}

advise the rate of stroke is 1.5 per every 1000 individuals with atrial fibrillation or a metallic heart valve, who stop anticoagulation for a period of 5 days. In those with a previous history of stroke the risk is 3 fold higher, in regards to venous thromboembolism the risk is highest during the first 3 months. All of these risks are increased further by surgery ${ }^{(12)}$. In the case of non-valvular atrial fibrillation, the calculation of a CHA2DS2-VASc score (congestive heart failure, hypertension, age $\geq 75$ years, diabetes mellitus, prior stroke, vascular disease, age 65-74, and female sex) may be helpful ${ }^{(13)}$. The American College of Chest Physicians (ACCP) suggest a score of $>2$ may be used to identify those at higher risk of thrombosis prior to a peri- operative interruption of anticoagulation ${ }^{(14)}$. Currently, there is no score validated for use during an episode of epistaxis. A meta-analysis showed that $10 \%$ of all acute coronary syndromes are preceded by aspirin withdrawal, however a large proportion of the individuals stopped aspirin prior to surgery that may in itself increase the thrombotic risk ${ }^{(15)}$. Clinicians have to balance an individual's risk of bleeding with their risk of recurrent thrombosis.

\section{Basic coagulation screen}

The utility of basic coagulation screening has been debated

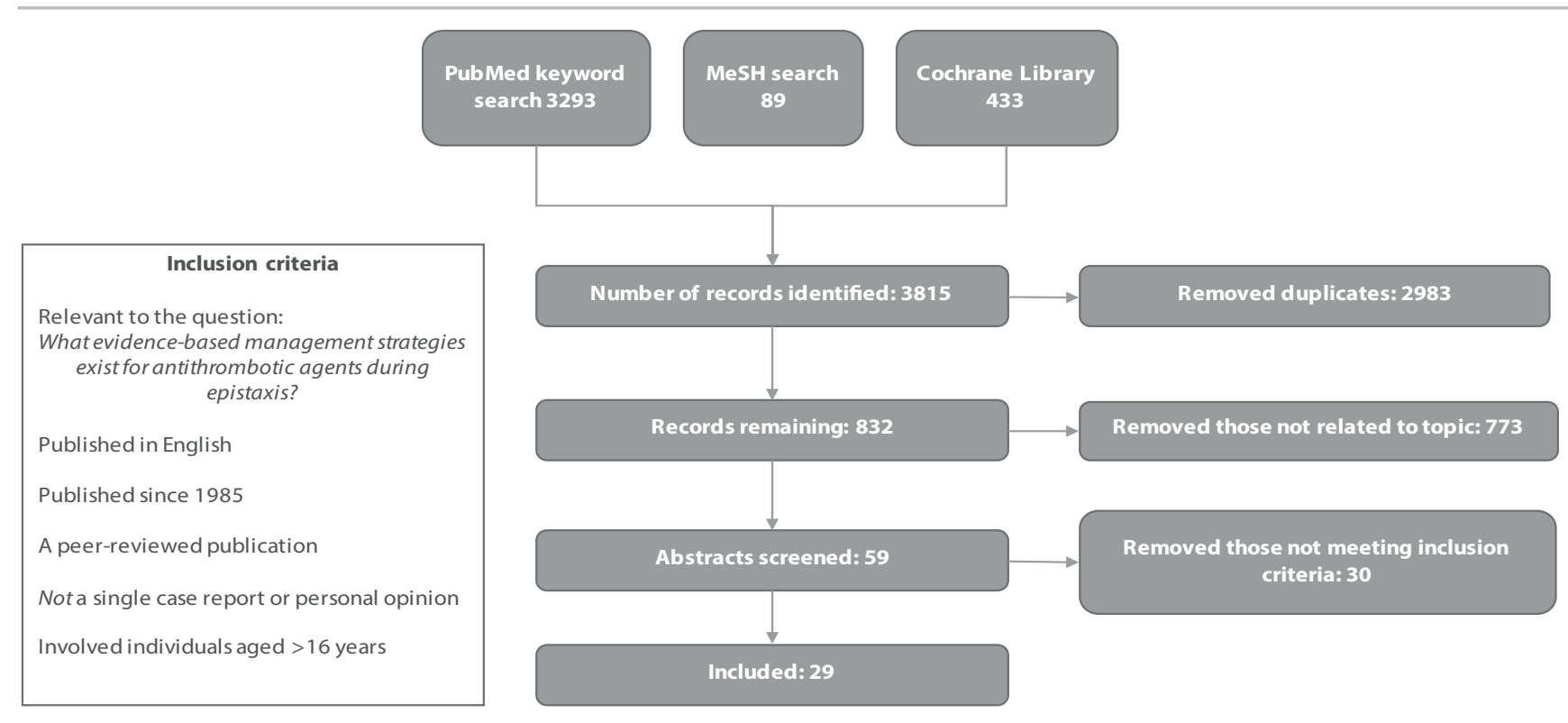

Figure 1. Summary of articles searched and inclusion criteria. 
Table 2. Potential effects on coagulation test, please note results will vary between individual laboratories.

\begin{tabular}{|c|c|}
\hline Agent & Potential effect on coagulation tests \\
\hline Warfarin & Prolonged PT and INR \\
\hline Dabigatran & Prolonged APTT and TT \\
\hline Rivaroxaban & Prolonged PT \\
\hline Apixaban & No effect \\
\hline Aspirin & No effect \\
\hline Clopidogrel & No effect \\
\hline
\end{tabular}

PT - prothrombin, APTT - activated partial thromboplastin time, INR international normalized ratio, TT - thrombin time.

in the literature. Three papers discuss the use of coagulation screens; two retrospective studies ${ }^{(16,17)}$ and one prospective ${ }^{(18)}$. All conclude that they should not be used routinely, but in individuals taking a vitamin $\mathrm{K}$ antagonist or with recurrent bleeding. Individuals taking newer oral anticoagulants were not discussed. It would however be advisable to perform coagulation tests in: anyone taking a vitamin $\mathrm{K}$ antagonist to look for supratherapeutic levels; cases with moderate to severe bleeding who may require reversal of anti-thrombotics; and individuals with a history of recurrent epistaxis who may have an underlying haemostatic problem.

Interpretation of the coagulation screen depends heavily upon the anti-thrombotic therapy used (Table 2). DOACs such as apixaban can have very little, if any, effect on the usual coagulation screen (prothrombin time, PT; activated partial thromboplastin time, APTT). Results will vary by laboratory and it is important to know the effect of anti-thrombotic drugs on locally used assays ${ }^{(19)}$. Many laboratories can now perform drug levels for DOACs but interpretation is difficult and haematology advice should be sought.

Some DOACs, such as Dabigatran and Rivaroxaban, are mainly excreted renally. Individuals taking such medication should have their renal function measured and the timing of their last dose carefully noted. In acute renal impairment it is very difficult to assess an individual's level of anticoagulation, even several days following the last dose ${ }^{(20)}$.

Topical and systemic drug therapies to promote haemostasis

One of the most commonly used agents in bleeding conditions is tranexamic acid. This works to prevent clot breakdown by binding to plasminogen and is therefore helpful to control bleeding. It can be administered either systemically (oral or intra- venous) or topically. A recent 5-year review of epistaxis admissions to a district general hospital suggested that up to $54 \%$ of individuals taking antithrombotic medication would have been suitable for tranexamic acid ${ }^{(21)}$.

There are nine studies relating to tranexamic acid use in epistaxis, three literature reviews ${ }^{(22-24)}$, one systemic review ${ }^{(25)}$, one retrospective review ${ }^{(21)}$ and four randomised control trials (RCTs) ${ }^{(26-29)}$. No study investigated the use of tranexamic acid in those individuals on antithrombotic medication.

Two RCTs comparing the use of nasal packs soaked in parenteral tranexamic acid to tetracycline for anterior bleeds, showed improved control of bleeding with tranexamic acid. Both excluded individuals with an INR $>1.5$ but no further details regarding antiplatelet use or anticoagulants other than vitamin $\mathrm{K}$ antagonists were given ${ }^{(26,27)}$. Two other RCTs investigated the use of tranexamic acid gel and tranexamic acid orally compared to placebo, neither showed any statistically significant differences ${ }^{(28,29)}$. A systemic review by Kamhieh et al. showed no benefit to oral tranexamic acid and no clear benefit to topical tranexamic acid ${ }^{24)}$. This review occurred prior to the second RCT demonstrating significant benefit with topical tranexamic acid. Topical tranexamic acid may be helpful in people taking anti-thrombotic therapy but currently, there is no specific study investigating its use.

There are several other topical and systemic agents that have been used in epistaxis management to promote haemostasis. However, only one study specifically addresses these agents in individuals taking anti-thrombotics. A small, uncontrolled, cohort of 35 patients on a mixture of anticoagulants were treated with a chitosan coated Meroce ${ }^{\circledR}$ pack. This resulted in haemostasis in $91 \%$ of cases up to 2 weeks. All patients were packed for 48 hours and anticoagulants were withdrawn in most. The authors advocate chitosan's natural cationic polysaccharide properties in haemostasis, but further research is needed ${ }^{(30)}$.

\section{Key points:}

1. All patients should have the reason for anti-thrombotic therapy identified and documented.

2. Comprehensive risk assessment must be undertaken prior to considering the withdrawal of anti-thrombotic therapy.

3. An INR should be measured in those on warfarin and a coagulation screen in cases of moderate, severe or recurrent bleeding. Local Haematology advice should be sought for those taking DOACs.

4. Systemic tranexamic acid is unproven.

5. There may be a role for topical tranexamic acid but there is currently little data in this population. 
Anti-platelet agents

There are an increasing number of anti-platelet agents, below we discuss two of the most commonly used, aspirin and clopidogrel.

\section{Mechanism of action: aspirin}

Aspirin is an irreversible inhibitor of the cyclooxygenase-1 (COX1) pathway, preventing the formation of arachidonic acid and thereby inhibiting this method of platelet activation. Absorbed through the gastrointestinal tract, it works in the portal system before being quickly deactivated in the liver. For this reason, it does not affect transfused platelets or those newly produced in the bone marrow. On average the bone marrow will produce $10 \%$ of the body's total platelet count each day. This equates to $50 \times 10^{\%} / \mathrm{L}$ of a normal $250 \times 10^{\%} / \mathrm{L}$ platelet count after two days of stopping aspirin ${ }^{(31)}$.

\section{Mechanism of action: clopidogrel}

Clopidogrel is a member of the thienopyridine drug class and irreversibly inhibits the ADP P2Y12 receptor. It is a pro-drug that is metabolised to an active metabolite. $85 \%$ of clopidogrel is converted to an inactive carboxylic acid metabolite and the remaining $15 \%$ into 2 -oxo-clopidogrel. It is the latter derivative that is further catalysed by the cytochrome P450 (CYP) pathway into the active metabolite ${ }^{(32,33)}$. Following discontinuation of the drug, the active metabolite continues to be formed and is able to affect both transfused and newly formed platelets.

\section{Reversal strategies: withdrawal of anti-platelet therapy} Withdrawal of anti-platelet therapy alone is unlikely to assist during an admission for epistaxis. A study of platelet function following 7 days of Clopidogrel in healthy volunteers has shown that the drugsa effects will continue for approximately 7 days following withdrawal ${ }^{(34)}$. A prospective randomised trial of aspirin in 38 healthy individuals showed that all bleeding times normalized 4 days after stopping aspirin, whereas platelet function testing was normal in all cases at 6 days. There was no difference between a $75 \mathrm{mg}$ versus a $300 \mathrm{mg}$ dose ${ }^{(35)}$.

\section{Reversal strategies: use of platelet transfusion}

There are no completed trials that have investigated the use of platelet transfusion in reversing the effects of anti-platelet therapies in the bleeding patient. Pruller et al. did show that some platelet function was restored if platelets were transfused to healthy volunteers who had been given aspirin and clopidogrel for 7 days ${ }^{(36)}$. Li et al. monitored platelet aggregation studies following the use of aspirin or clopidogrel, their results were similar to those previously mentioned with platelet aggregation correcting at 4-days post aspirin and 10-days post clopidogrel. A second cohort was also treated with aspirin or clopidogrel but platelet aggregation was performed while plasma was mixed with donor platelets. Platelet testing normalised in the aspirin group following mixing with $30 \%$ of donor platelets but only after the addition of greater than $90 \%$ did testing normalize following clopidogrel ${ }^{(37)}$. The PATCH study has recently completed recruitment and hopes to report soon on the use of platelet transfusion in reversing anti-platelet therapy in those with an intra-cranial bleed ${ }^{(38)}$.

\section{Overview of studies}

Seven studies were found relating to anti-platelet agents and epistaxis: two literature reviews ${ }^{(39,40)}$ and two prospective observational studies ${ }^{(5,6)}$ and three retrospective ${ }^{(41-43)}$. These are summarised in Table 3. The evidence suggests an association between anti-platelet medication and the risk of developing epistaxis. Individuals taking anti-platelet medication, have a longer and more complicated hospital stay. There are no trials investigating the management of anti-platelet agents during epistaxis.

\section{Key points:}

1. Withdrawal of anti-platelet agents is unlikely to help in the acute epistaxis setting.

2. There is currently no evidence to support platelet transfusion during epistaxis, however it has been shown to reverse the effects to some degree in healthy volunteers.

\section{Vitamin K antagonists}

Mechanism of action: vitamin K antagonists

Warfarin is the most commonly used vitamin K antagonist; they work by inhibiting the production of the vitamin $\mathrm{K}$ dependent clotting factors (II, VII, IX and X). The intensity of anticoagulation can be measured using an INR (International Normalized Ratio) that by definition does not vary between laboratories.

\section{Continuing anti-thrombotics}

There is increasing evidence, in the case of mild and moderate bleeding, that anticoagulation with vitamin $\mathrm{K}$ antagonists (e.g. warfarin) can be continued during an epistaxis admission. Srinivasan et al. compared outcomes in a small cohort of epistaxis patients, 20 on warfarin and 20 age and sex matched controls, not on warfarin. Those with an INR within their intended range were continued on warfarin. No difference in duration of hospital stay was found between the two groups ${ }^{(44)}$. A retrospective study performed by Bola et al. reviewed the outcomes of 176 individuals with epistaxis, 54 of whom were taking warfarin. Providing their INR was not supra-therapeutic, warfarin was continued throughout the admission. Only 4 individuals required surgery and all were in the group who did not take warfarin. Both groups had a similar length of stay in hospital. Individuals on warfarin had a readmission rate of $7.4 \%$ compa- 
Table 3. Summary of studies investigating anti-thrombotic agents and epistaxis. Excludes literature reviews.

\begin{tabular}{|c|c|c|c|c|}
\hline \multicolumn{5}{|c|}{ Anti-platelet agents and epistaxis } \\
\hline Authors & Type of study & Methodology & Main finding & Limitations \\
\hline $\begin{array}{l}\text { Abrich et al, } \\
2014^{(41)}\end{array}$ & retrospective & $\begin{array}{l}461 \text { individuals with at least } 2 \\
\text { episodes of epistaxis in } 3 \text { years, } \\
\text { data gathered over } 20 \text { years }\end{array}$ & $\begin{array}{l}\text { Aspirin and clopidogrel did not seem to } \\
\text { increase the risk of recurrent epistaxis }\end{array}$ & $\begin{array}{l}\text { Retrospective, did not consider } \\
\text { anti- thrombotic management } \\
\text { strategies }\end{array}$ \\
\hline $\begin{array}{l}\text { Smith et al, } \\
2011^{(5)}\end{array}$ & $\begin{array}{l}\text { prospective, } \\
\text { observational }\end{array}$ & $\begin{array}{l}\text { Reviewed } 290 \text { cases of epistaxis } \\
\text { that presented to one hospital } \\
\text { over a } 7 \text { month period }\end{array}$ & $\begin{array}{l}\text { Antithrombotic agents were taken by } \\
\text { older individuals and led to longer, more } \\
\text { complicated hospital stays }\end{array}$ & Small sample size \\
\hline $\begin{array}{l}\text { Soyka et al, } \\
2010^{(6)}\end{array}$ & $\begin{array}{l}\text { prospective, } \\
\text { observational }\end{array}$ & $\begin{array}{l}591 \text { cases of epistaxis recruited } \\
\text { at } 1 \text { centre over } 1 \text { year. }\end{array}$ & $\begin{array}{l}\text { Individuals on aspirin were more likely to } \\
\text { need surgery, had a higher severity score } \\
\text { and high risk of recurrence. Asprin use } \\
\text { did not affect length of hospital stay. }\end{array}$ & $\begin{array}{l}\text { Did not consider management } \\
\text { strategies for anti-thrombotics. }\end{array}$ \\
\hline $\begin{array}{l}\text { Rainsbury et } \\
\text { al, } 2009^{(42)}\end{array}$ & retrospective & $\begin{array}{l}\text { Reviewed 10,241 electronic ge- } \\
\text { neral practice records, } 69 \text { cases } \\
\text { of epistaxis } \\
\text { were found. }\end{array}$ & $\begin{array}{l}\text { Aspirin and clopidogrel increased the risk } \\
\text { of epistaxis by a similar amount }\end{array}$ & $\begin{array}{l}\text { Retrospective, did not account } \\
\text { for self- } \\
\text { medication or epistaxis managed } \\
\text { at home. }\end{array}$ \\
\hline $\begin{array}{l}\text { Tay et al, } \\
1998^{(43)}\end{array}$ & retrospective & $\begin{array}{l}326 \text { epistaxis cases reviewed } \\
\text { over } 3 \text { years, investigated use } \\
\text { of non-steroidal anti-inflamma- } \\
\text { tories. }\end{array}$ & $\begin{array}{l}\text { Aspirin associated with increased risk of } \\
\text { epistaxis }\end{array}$ & $\begin{array}{l}\text { Not accounting for self-medica- } \\
\text { tion. }\end{array}$ \\
\hline \multicolumn{5}{|c|}{ Vitamin $\mathrm{K}$ antagonists and epistaxis } \\
\hline Authors & Type of study & Methodology & Main finding & Limitations \\
\hline $\begin{array}{l}\text { Bola et al, } \\
2016^{(3)}\end{array}$ & retrospective & $\begin{array}{l}176 \text { epistaxis cases who required } \\
\text { hospital admission were revie- } \\
\text { wed over a } 12 \text { month period in } \\
1 \text { centre. }\end{array}$ & $\begin{array}{l}\text { Safe to continue warfarin when INR is } \\
\text { not supra-therapeutic. Individuals on } \\
\text { warfarin had longer hospital stays. }\end{array}$ & $\begin{array}{l}\text { Retrospective and did not consi- } \\
\text { der newer oral anticoagulants. }\end{array}$ \\
\hline $\begin{array}{l}\text { Johansen et } \\
\text { al, } 2015^{(48)}\end{array}$ & $\begin{array}{l}\text { systematic } \\
\text { review }\end{array}$ & $\begin{array}{l}\text { Reviewed } 4 \text { randomised control- } \\
\text { led trials regarding the reversal } \\
\text { of vitamin } \mathrm{K} \text { antagonists with } \\
\text { prothrombin complex. }\end{array}$ & $\begin{array}{l}\text { Prothrombin complex does not reduce } \\
\text { mortality or the need for blood transfu- } \\
\text { sion but is an alternative to fresh frozen } \\
\text { plasma. }\end{array}$ & $\begin{array}{l}\text { No study considered epistaxis } \\
\text { specifically. }\end{array}$ \\
\hline $\begin{array}{l}\text { Abrich et al, } \\
2014^{(41)}\end{array}$ & retrospective & $\begin{array}{l}461 \text { individuals who had at least } \\
2 \text { episodes of epistaxis in } 3 \text { years, } \\
\text { data gathered over } 20 \text { years. }\end{array}$ & $\begin{array}{l}\text { Warfarin use increased the risk of epsi- } \\
\text { taxis, regardless of INR. }\end{array}$ & $\begin{array}{l}\text { Retrospective, did not consider } \\
\text { anti-thrombotic management } \\
\text { strategies. }\end{array}$ \\
\hline $\begin{array}{l}\text { Smith et al, } \\
2011^{(5)}\end{array}$ & $\begin{array}{l}\text { prospective, } \\
\text { observational }\end{array}$ & $\begin{array}{l}\text { Reviewed } 290 \text { cases of epistaxis } \\
\text { that presented to one hospital } \\
\text { over a } 7 \text { month period. }\end{array}$ & $\begin{array}{l}\text { Antithrombotic agents taken by older } \\
\text { individuals and led to longer, more com- } \\
\text { plicated hospital stays. }\end{array}$ & Small sample size \\
\hline 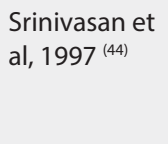 & $\begin{array}{l}\text { prospective, } \\
\text { observational }\end{array}$ & $\begin{array}{l}0 \text { individuals taking warfarin } \\
\text { who presented with epsitaxis } \\
\text { were compared to age and sex } \\
\text { matched controls. }\end{array}$ & $\begin{array}{l}\text { Warfarin can be continued, if not supra- } \\
\text { therapeutic, without increased risk of } \\
\text { re-bleeding. }\end{array}$ & Small sample size \\
\hline $\begin{array}{l}\text { Denholm et } \\
\text { al, } 1993^{(4)}\end{array}$ & $\begin{array}{l}\text { prospective, } \\
\text { observational }\end{array}$ & $\begin{array}{l}\text { Over an } 18 \text { month period, } 20 \\
\text { individuals presenting with } \\
\text { epistaxis whilst taking warfarin } \\
\text { were reviewed. }\end{array}$ & $\begin{array}{l}\text { Individuals taking warfarin had a longer } \\
\text { hospital stay, usually whilst their warfarin } \\
\text { was restarted. }\end{array}$ & $\begin{array}{l}\text { All warfarin discontinued and } \\
\text { reversed with fresh frozen plasma } \\
\text { if bleeding continued despite } \\
\text { packing. Fresh frozen plasma } \\
\text { is no longer recommended for } \\
\text { warfarin reversal. }\end{array}$ \\
\hline
\end{tabular}

red to $1.1 \%$ in the group not on anticoagulation, however this result was not statistically significant ${ }^{(3)}$. Providing an individual's INR is not supra-therapeutic and the bleeding is controlled, it would therefore be appropriate to consider continuing warfarin therapy.

\section{Reversal strategies: vitamin K antagonists (e.g. warfarin)}

A proposed management strategy for vitamin $\mathrm{K}$ antagonists is described below and shown in Figure 2. As discussed, it is not always necessary to reverse these agents; during an episode of mild epistaxis or controlled moderate bleeding they may be continued if the INR is therapeutic or sub-therapeutic. If clinicians were confident the bleeding was controlled and the individual had a significant risk from the withdrawal of anticoagulation, then vitamin $\mathrm{K}$ antagonists could simply be withheld until the INR was within range. British Committee on Standards in Haematology ( $\mathrm{BCSH}$ ) guidelines suggest vitamin $\mathrm{K}$ be given above an INR level of 8 to prevent spontaneous bleeding. In the 


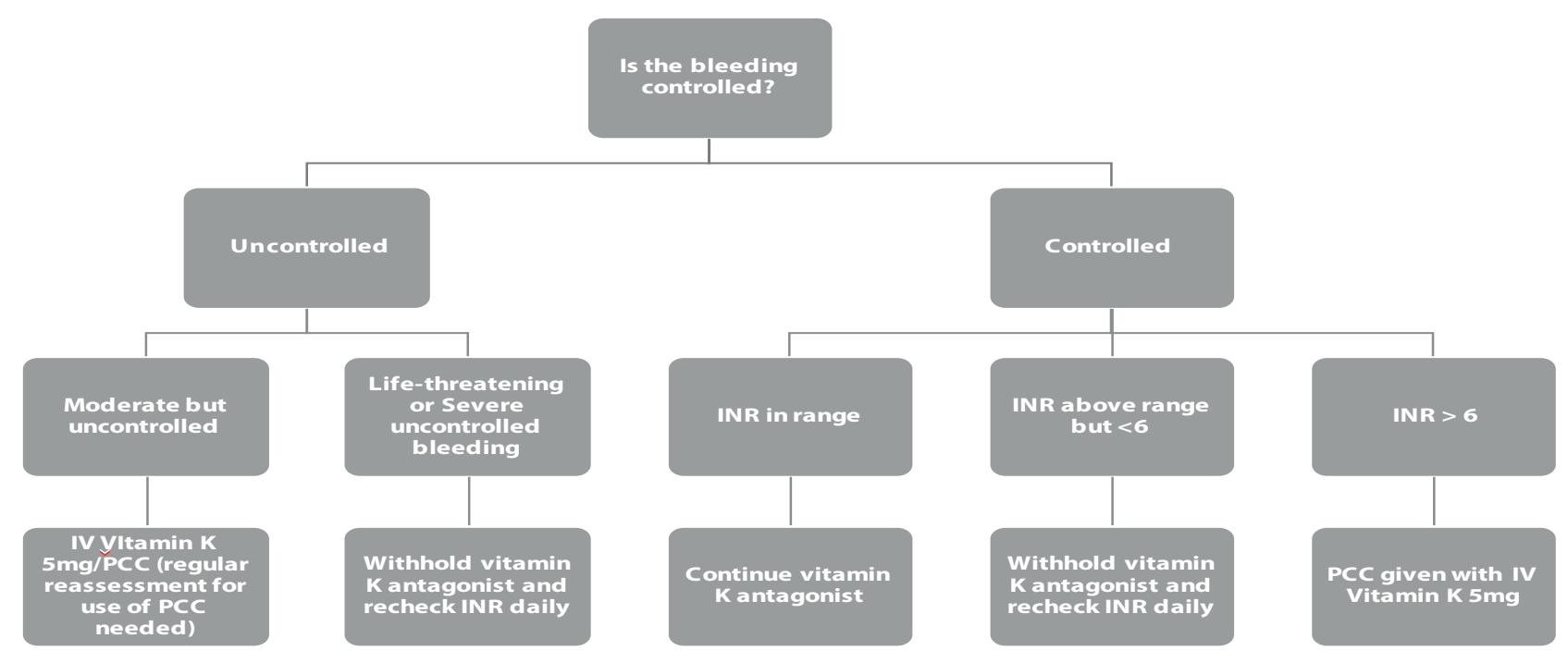

Figure 2. Flow chart of suggested management of vitamin K antagonists during epistaxis. PCC: prothrombin complex concentrate, IV: intravenous; INR: international normalized ratio.

context of recent epistaxis however, we would suggest an INR level $>6$ is associated with higher risks of bleeding and therefore should be treated ${ }^{(45)}$. Intravenous vitamin $\mathrm{K}(1-2 \mathrm{mg})$ can be used to reverse vitamin $\mathrm{K}$ antagonists when immediate reversal is not needed; generally intravenous takes 6-8 hours to take effect unlike oral vitamin $\mathrm{K}$ that takes 24 hours ${ }^{(46)}$. In the case of life-threatening bleeding, immediate reversal should be given in the form of prothrombin complex concentrate (PCC). PCC has been associated with an increased risk of thrombosis and so should be reserved only for life-threatening bleeds ${ }^{(19)}$. Fresh frozen plasma should only be considered if PCC is unavailable as it is suboptimal at reversing vitamin $\mathrm{K}$ antagonists ${ }^{(19,47)}$. As with all severe and life-threatening bleeding, there should be a low threshold for discussing with haematology.

\section{Overview of studies}

Seven studies were found relating to vitamin $\mathrm{K}$ antagonists and epistaxis: three prospective observational studies ${ }^{(5,44,47)}$, two retrospective ${ }^{(3,40)}$, one literature review ${ }^{(40)}$ and one 1 systematic review ${ }^{(48)}$. No studies specifically investigated reversal of vitamin $\mathrm{K}$ antagonists in epistaxis patients (Table 3 ).

\section{Key Points:}

1. Vitamin $\mathrm{K}$ antagonists may be continued if bleeding is mild or moderate and controlled, providing the INR is not supra-therapeutic.

2. INR levels above 6 should be reversed with vitamin $K$ 1-2mg IV.

3. INR levels above therapeutic range but $<6$ may be managed by withholding the drug.

4. Life-threatening bleeds should be reversed with prothrombin complex concentrate (given with vitamin $\mathrm{K}$

\section{5mg IV).}

Direct oral anticoagulants (DOACs)

Mechanism of action: direct thrombin inhibitors and factor Xa inhibitors

Coagulation is ultimately the formation of a fibrin clot through the cleavage of fibrinogen by thrombin. The production of thrombin from prothrombin requires activated factor X (Xa) that forms part of the prothrombinase complex (Figure 3).

There are two new classes of direct oral anticoagulants: direct thrombin inhibitors (e.g. dabigatran) and factor Xa inhibitors (e.g. rivaroxaban). As with other anti-thrombotic agents, an initial assessment should be made to decide whether these medications should be stopped. Unlike the other anti-thrombotics they have a short half-life (approximately 8-12 hours) and withholding them can be very effective; providing an individual's renal function is maintained in the case of drugs such as dabigatran.

Reversal strategies: direct thrombin inhibitors (e.g. dabigatran)

In situations of severe or uncontrolled moderate bleeding, reversal may be necessary. Activated charcoal administered within 2 hours of dabigatran ingestion can be efficacious and dabigatran can also be removed through renal dialysis ${ }^{(19)}$. Idarucizumab is a monoclonal antibody and has recently become available as a reversal agent for dabigatran, two doses of $2.5 \mathrm{~g}$ IV given 15 minutes apart are recommended ${ }^{(49)}$.

Reversal strategies: Xa inhibitors (e.g. rivaroxaban) The class of Xa inhibitors include: rivaroxaban, apixaban and 


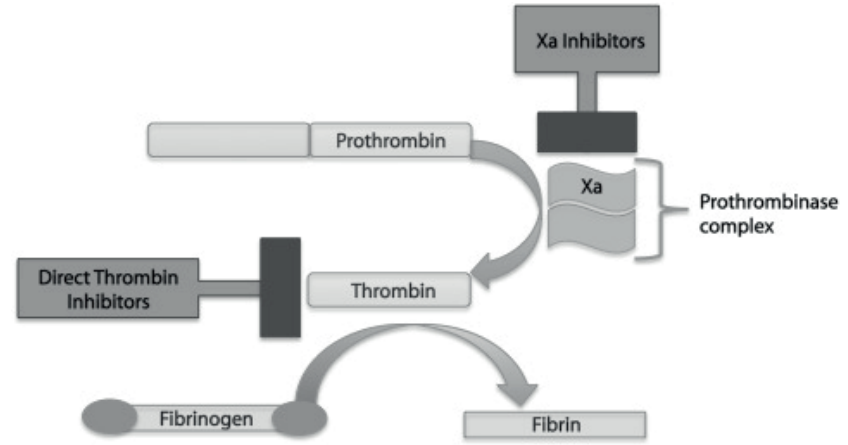

Figure 3. Mechanism of direct thrombin and Xa inhibitors. Xa-activated Factor X.

edoxaban. Currently there is no reversal agent. In situations of life-threatening bleeding the use of PCC is recommended but the evidence for its use is mainly from animal models and healthy volunteers ${ }^{(50,51)}$.

Andexanet alfa is a modified, catalytically inactive, factor Xa molecule that binds all Xa inhibitors and is currently being investigated as a reversal agent. Currently it has been shown to be effective in animal models and healthy volunteers ${ }^{(52)}$.

\section{Overview of studies}

There were no studies investigating the management of direct oral anticoagulants in epistaxis.

\section{Key Points}

\section{Direct oral anticoagulants (DOACs) have a short half-life}

(approximately 8-12 hours) and withholding them can be very effective.

2. Dabigatran can be reversed by activated charcoal, dialysis and idarucizumab.

3. Xa inhibitors cannot currently be reversed, but a reversal agent is in development.

4. PCC should be used to assist in life threatening bleeding with $\mathrm{Xa}$ inhibitors, but there is little evidence for efficacy.

Immediate reversal

A summary of available evidence relating to the immediate reversal of antithrombotic agents is given in Table 4. An overview of anti-thrombotic management is given in Figure 4.

\section{Discussion}

An ageing population, an increasing use of anti-thrombotic agents and the rise in popularity of DOACs, is likely to have a significant impact on epistaxis admissions and management. A recent meta-analysis has shown DOACs to have a lower allcause mortality than vitamin $\mathrm{K}$ antagonists and current ACCP guidance relating to pulmonary embolism recommends DOACs for first line treatment in non-cancer patients ${ }^{(53,54)}$. With the increased use of DOACs, studies into the reversal of these agents in epistaxis will become increasingly important to management. Otolaryngologists must keep up to date with the local availability of reversal agents to new DOACs.

While we would always advise close collaboration with haema-

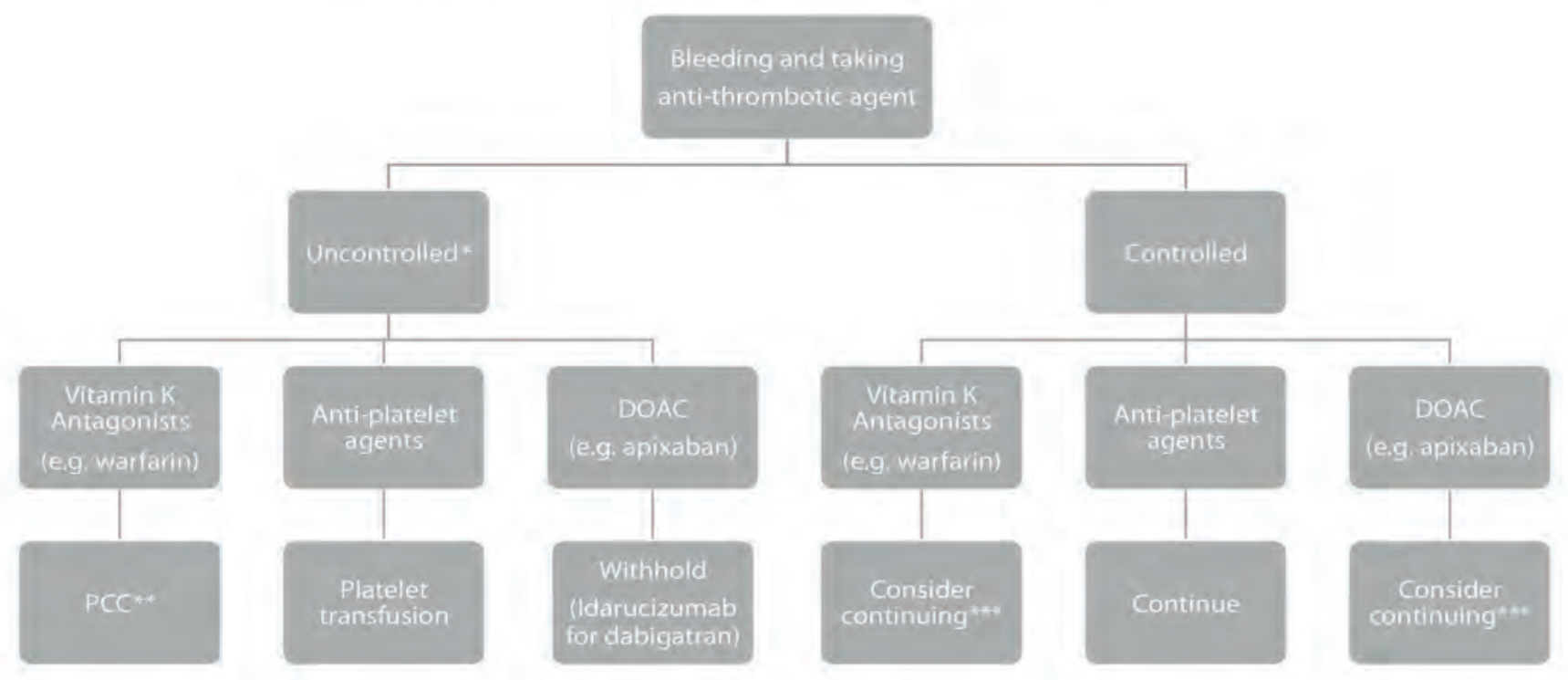

Figure 4. Summary of anti-thrombotic management during an episode of epistaxis. *Consider contacting Haematology for advice. ${ }^{* *}$ See Figure 2 for reversal of vitamin $\mathrm{K}$ antagonists. ${ }^{* * *}$ Consider the reason anti-thrombotic medication was administered to evaluate risk of further bleeding versus risk of thrombotic complications. PCC- prothrombin complex, DOAC- direct oral anticoagulant. 
Table 4. Summary of recommendations for immediate reversal and available evidence.

Antithrombotic Agent Immediate Reversal Strategies

\begin{tabular}{|c|c|c|}
\hline Aspirin & $\begin{array}{l}\text { Withhold } \\
\text { Platelet transfusion }\end{array}$ & $\begin{array}{l}\text { In healthy volunteers it takes } 4-6 \text { days for platelet function tests to normalize }{ }^{(11,36)} \text {. } \\
\text { In vitro mixing shows some correction }{ }^{(37,38)} \text {. }\end{array}$ \\
\hline Clopidogrel & $\begin{array}{l}\text { Withhold } \\
\text { Platelet transfusion }\end{array}$ & $\begin{array}{l}\text { In healthy volunteers it takes } 7-10 \text { days for platelet function tests to normalize }{ }^{(11,35)} \text {. } \\
\text { Some in vitro evidence but high percentage of donor platelets needed for effect }{ }^{(37,38)} \text {. }\end{array}$ \\
\hline Vitamin $\mathrm{K}$ antagonists & $\begin{array}{l}\text { Prothrombin Complex } \\
\text { Concentrate with } \\
\text { Vitamin K } 5 \mathrm{mg} \mathrm{IV}\end{array}$ & Good evidence that it is efficacious ${ }^{(19)}$. \\
\hline Dabigatran & $\begin{array}{l}\text { Idarucizumab } \\
\text { Activated charcoal } \\
\text { Haemodialysis }\end{array}$ & $\begin{array}{l}\text { Shown to be efficacious in bleeding individuals }{ }^{(49)} \text {. } \\
\text { Evidence in animals and in vitro studies }{ }^{(19)} \text {. } \\
\text { Evidence in animal model and case reports in bleeding patients }{ }^{(19)} \text {. }\end{array}$ \\
\hline Rivaroxaban & $\begin{array}{l}\text { Prothrombin Complex } \\
\text { Concentrate }\end{array}$ & $\begin{array}{l}\text { Limited evidence for efficacy, some studies in healthy volunteers and animal models } \\
(50,51) \text {. }\end{array}$ \\
\hline Apixaban & $\begin{array}{l}\text { Prothrombin Complex } \\
\text { Concentrate }\end{array}$ & $\begin{array}{l}\text { Limited evidence for efficacy, some studies in healthy volunteers and animal models } \\
(50,51) \text {. }\end{array}$ \\
\hline
\end{tabular}

tology units in cases of epistaxis on anti-thrombotics, otolaryngologists and other clinicians managing epistaxis must also have a clear understanding of the impact of these agents. We present a systematic review of the evidence for the management of anti-thrombotic agents in epistaxis. Greater understanding of these agents and the potential to reverse their effects has the possibility to reduce the burden of epistaxis management on hospital units. There is currently a dearth of evidence for the management of anti-thrombotic agents in epistaxis and further quality studies could have a massive impact on future management in this area.

Critical to the management of these patients is the assessment of both bleeding and thrombotic risk. The creation of a standardised bleeding score particular to epistaxis, that included risk of re-bleeding and re-admission, would be very useful in this area. Further study would also be beneficial in the use of anti-fibrinolytics. Tranexamic acid has been shown to improve outcomes when used in bleeding due to trauma and is currently being investigated in other kinds of bleeding. Potentially topical tranexamic acid could have a role in the management of individuals on anti-thrombotic therapy but further investigation is needed. The use of platelet transfusion in patients on anti-platelets has also the potential to be a useful treatment in epistaxis but specific high quality studies in epistaxis would also be useful.

There are numerous studies comparing different interventions, such as absorbable versus non- absorbable packing, surgical interventions and other methods of epistaxis control. However, we found no studies specifically investigating these techniques in individuals taking anti- thrombotic agents. Given the lack of evidence specific to this patients group we would advocate using the best available evidence based management, based on all comers with epistaxis. While also considering the possible adjunctive intervention available in this patient group.

Hereditary hemorrhagic telangiectasia ( $\mathrm{HHT}$ ) is another example of treatment resistant epistaxis. While there has been little research into the management of acute epistaxis in those taking antithrombotic medication, there have been large trials considering the best management of epistaxis during $\mathrm{HHT}$. Several of these systemic agents considered in HHT management could be evaluated in the management of anticoagulated patients with epistaxis ${ }^{(56,57)}$.

This systematic review has been limited by the paucity of data and prospective studies. All studies looking directly at epistaxis and anti-thrombotics were cohort observational studies. There is a need for randomised controlled trials to optimise the management of anticoagulation during an episode of epistaxis. We have covered the majority of anti- thrombotic agents used currently, there are however other agents used, and in development, not covered by this review, but we hope the basic principles of management will still be relevant.

\section{Conclusion}

This review is intended as a guide for clinicians, to advise on the most up to date management and identify areas for future research in epistaxis. However, the authors would always advocate the close multidisciplinary management of anticoagulated epistaxis patients by otolaryngologists, haematologists and cardiologists. 


\section{Authorship contribution}

Both authors contributed to the conception and writing of article. KMM completed the systemic review.

\section{Conflict of interest}

The authors declare that there is no conflict of interest.

\section{References}

1. Walker TW, Macfarlane TV, McGarry GW. The epidemiology and chronobiology of epistaxis: an investigation of Scottish hospital admissions 1995-2004. Clin Otolaryngol. 2007;32(5):361-5.

2. Biggs TC, Baruah P, Mainwaring J, Harries PG, Salib RJ. Treatment algorithm for oral anticoagulant and antiplatelet therapy in epistaxis patients. J Laryngol Otol. 2013;127(05):483-8

3. Bola S, Marsh R, Braggins S, Potter C, Hickey $S$. Does the continuation of warfarin change management outcomes in epistaxis patients?. J Laryngol Otol. 2016:130(3):25660 .

4. Denholm SW, Maynard CA, Watson HG Warfarin and epistaxis - a case controlled study. J Laryngol Otol. 1993;107(03):195-6.

5. Smith J, Siddiq S, Dyer C, Rainsbury J, Kim D. Epistaxis in patients taking oral anticoagulant and antiplatelet medication: prospective cohort study. J Laryngol Otol. 2011;125(01):38-42.

6. Soyka MB, Rufibach K, Huber A, Holzmann D. Is severe epistaxis associated with acetylsalicylic acid intake?. Laryngoscope. 2010;120(1):200-7.

7. Purkey MR, Seeskin Z, Chandra R. Seasonal variation and predictors of epistaxis. Laryngoscope. 2014;124(9):2028-33.

8. Andreotti F, Rocca B, Husted S, Ajjan RA, Ten Berg J, Cattaneo M, et al. Antithrombotic therapy in the elderly: expert position paper of the European Society of Cardiology Working Group on Thrombosis. Eur Heart J. 2015;36(46):3238-49.

9. Bermüller $C$, Bender $M$, Brögger $C$, Petereit F, Schulz M. [Epistaxis and anticoagulation-a medical and economic challenge?] Laryngo-rhino-otologie. 2014 Apr;93(4):24955

10. Choudhury N, Sharp HR, Mir N, Salama NY Epistaxis and oral anticoagulant therapy. Rhinology. 2004;42(2):92-7.

11. Spielmann PM, Barnes ML, White PS Controversies in the specialist management of adult epistaxis: an evidence-based review. Clin Otolaryngol. 2012;37(5):382-9

12. Keeling D, Baglin T, Tait C, Watson H, Perry D, Baglin C, Kitchen S, Makris M. Guidelines on oral anticoagulation with warfarin-fourth edition. Br J Haematol. 2011;154(3):311-24.

13. Camm AJ, Kirchhof P, Lip GY, et al. Guidelines for the management of atria fibrillation. Eur Heart J. 2010 Aug 29:ehq278.

14. Douketis JD, Spyropoulos AC, Spencer FA, et al. Perioperative management of antithrombotic therapy: antithrombotic therapy and prevention of thrombosis: American College of Chest Physicians evidencebased clinical practice guidelines. Chest $J$. 2012;141(2_suppl):e326S-50S
15. Burger W, Chemnitius JM, Kneissl GD, Rücker G. Low-dose aspirin for secondary cardiovascular prevention-cardiovascular risks after its perioperative withdrawal versus bleeding risks with its continuation-review and meta-analysis. J Int Med. 2005;257(5):399-414.

16. Shakeel M, Trinidade A, Iddamalgoda $T$, Supriya M, Ah-See KW. Routine clotting screen has no role in the management of epistaxis: reiterating the point. Eur Arch Oto-Rhino-Laryngol. 2010; 267(10), 1641-44

17. Thaha MA, Nilssen EL, Holland S, Love $G$, White PS. Routine coagulation screening in the management of emergency admission for epistaxis-is it necessary?. J Laryngol Otol. 2000;114(01):38-40.

18. Soyka MB, Holzmann D. Should we test the prothrombin time in anticoagulated epistaxis patients?. Allergy Rhinol. 2013;4(1):e52-3.

19. Kitchen S, Gray E, Mackie I, Baglin T, Makris M. Measurement of non-Coumarin anticoagulants and their effects on tests of Haemostasis: Guidance from the British Committee for Standards in Haematology. $\mathrm{Br} J$ Haematol. 2014;166(6):830-41.

20. Makris M, Veen JJ, Tait CR, Mumford AD, Laffan M. Guideline on the management of bleeding in patients on antithrombotic agents. Br J Haematol. 2013; 160(1), 35-46.

21. Jervis S, Saunders T, Belcher J, Skinner D. Evaluating three hundred and fifty two admissions and predictors of readmissions for epistaxis-is it time to reevaluate tranexamic acid in epistaxis? Clin Otolaryngol. 2015 Dec 18. doi: 10.1111/ coa.12609. [Epub ahead of print]

22. Fox $H$, Hunter F. BET 1: Intravenous tranexamic acid in the treatment of acute epistaxis. Emergency Medicine Journal. 2015 Dec 1;32(12):969-70.

23. Hilton L. Best evidence topic reports. BET 3: Topical intranasal tranexamic acid for spontaneous epistaxis. Emerg Med J. 2014;31(5):436-7.

24. Kamhieh Y, Fox H. Tranexamic acid in epistaxis: a systematic review. Clin Otolaryngol. 2016 Mar 4. doi: 10.1111/ coa.12645.

25. Ker K, Beecher D, Roberts I. Topical application of tranexamic acid for the reduction of bleeding. Cochrane Database Syst Rev. 2013 Jan 1:7.

26. Clinkard D, Barbic D. Tranexamic Acid for Epistaxis-A Promising Treatment That Deserves Further Study. CJEM. 2016;18(01):72-3.

27. Zahed R, Moharamzadeh P, AlizadehArasi S, Ghasemi A, Saeedi M. A new and rapid method for epistaxis treatment using injectable form of tranexamic acid topically: a randomized controlled trial. Am J Emer
Med. 2013;31(9):1389-92.

28. Tibbelin A, Aust R, Bende M, Holgersson M, Petruson B, Rundcrantz H, Ålander U. Effect of local tranexamic acid gel in the treatment of epistaxis. ORL. 1995;57(4):207-9.

29. White A, O'Reilly BF. Oral tranexamic acid in the management of epistaxis. Clin Otolaryngol Allied Sci. 1988;13(1):11-6.

30. Kourelis K, Shikani AH. Effectiveness of chitosan-based packing in 35 patients with recalcitrant epistaxis in the context of coagulopathy. Clinical Otolaryngology. 2012:37(4):309-13.

31. Sarode R. How do I transfuse platelets (PLTs) to reverse anti-PLT drug effect?(CME). Transfusion. 2012;52(4):695-701.

32. Jarvis B, Simpson K. Clopidogrel. Drugs. 2000;60(2):347-77

33. Kazui M, Nishiya $Y$, Ishizuka $T$, et al. Identification of the human cytochrome P450 enzymes involved in the two oxidative steps in the bioactivation of clopidogrel to its pharmacologically active metabolite. Drug Metab Dispos. 2010;38(1):92-9.

34. Weber AA, Braun M, Hohlfeld T, Schwippert B, Tschöpe D, Schrör K. Recovery of platelet function after discontinuation of clopidogrel treatment in healthy volunteers. $\mathrm{Br}$ J Clin Pharmacol. 2001; 52(3), 333-6.

35. Cahill RA, McGreal GT, Crowe BH, et al. Duration of increased bleeding tendency after cessation of aspirin therapy. J Am Coll Surg. 2005;200(4):564-73

36. Prüller F, Drexler C, Archan S, Macher S, Raggam RB, Mahla E. Low platelet reactivity is recovered by transfusion of stored platelets: a healthy volunteer in vivo study. J Thromb Haemost. 2011;9(8):1670-3.

37. Li C, Hirsh J, Xie C, Johnston MA, Eikelboom JW. Reversal of the anti-platelet effects of aspirin and clopidogrel. J Thromb Haemost. 2012;10(4):521-8.

38. de Gans K, de Haan RJ, Majoie CB,et al. PATCH: platelet transfusion in cerebral haemorrhage: study protocol for a multicentre, randomised, controlled trial. BMC Neurol. 2010;10(1):19.

39. Melia L, McGarry GW. Epistaxis: update on management. Curr Opin Otolaryngol Head Neck Surg. 2011;19(1):30-5.

40. Trotter MI, De R, Drake-Lee A. Evidencebased management of epistaxis in adults. $\mathrm{Br}$ J Hosp Med. 2006;67(12):651-3.

41. Abrich V, Brozek A, Boyle TR, Chyou PH, Yale $\mathrm{SH}$. Risk factors for recurrent spontaneous epistaxis. Mayo Clin Proc. 2014;89(12):163643.

42. Rainsbury JW, Molony NC. Clopidogrel versus low-dose aspirin as risk factors for epistaxis. Clin Otolaryngol. 2009;34(3):232-5.

43. Tay HL, McMahon AD, Evans JM, MacDonald TM. Aspirin, nonsteroidal anti-inflammatory drugs, and epistaxis. A regional record link- 
age case control study. Ann Otol Rhino Laryngol. 1998;107(8):671-4.

44. Srinivasan V, Patel H, John DG, Worsley A Warfarin and epistaxis: should warfarin always be discontinued?. Clin Otolaryngol Allied Sci. 1997;22(6):542-4.

45. Hylek EM, Chang Y, Skates SJ, Hughes RA, Singer DE. Prospective study of the outcomes of ambulatory patients with excessive warfarin anticoagulation. Arch Int Med. 2000;160(11):1612-7.

46. Watson HG, Baglin T, Laidlaw SL, Makris M Preston FE. A comparison of the efficacy and rate of response to oral and intravenous Vitamin $\mathrm{K}$ in reversal of over-anticoagulation with warfarin. $\mathrm{Br} J$ Haematol. 2001;115(1):145-9.

47. Makris M, Greaves M, Phillips WS, Kitchen S, Rosendaal FR, Preston EF. Emergency oral anticoagulant reversal: the relative efficacy of infusions of fresh frozen plasma and clotting factor concentrate on correction of the coagulopathy. Thromb Haemost. 1997;77(3):477-80.

48. Johansen M, Wikkelsø A, Lunde J, Wetterslev J, Afshari A. Prothrombin complex concentrate for reversal of vitamin $\mathrm{K}$ antagonist treatment in bleeding and non-bleeding patients. Cochrane Database Syst Rev. 2015
Jan 1;7.

49. Pollack CV Jr, Reilly PA, Eikelboom J, et al. Idarucizumab for dabigatran reversal. N Engl J Med. 2015;373(6):511-20.

50. Godier A, Miclot A, Le Bonniec B, et al. Evaluation of prothrombin complex concentrate and recombinant activated factor VII to reverse rivaroxaban in a rabbit model. Anesthesiology, 2012;116(1), 94-102.

51. Eerenberg ES, Kamphuisen PW, Sijpkens MK, Meijers JC, Buller HR, Levi M. Reversal of rivaroxaban and dabigatran by prothrombin complex concentrate a randomized, placebo-controlled, crossover study in healthy subjects. Circulation. 2011;124(14) 1573-79.

52. Siegal DM, Curnutte JT, Connolly SJ, et al. Andexanet alfa for the reversal of factor Xa inhibitor activity. N Engl J Med. 2015;373(25):2413-24

53. Chai-Adisaksopha C, Hillis C, Isayama T, Lim W, lorio A, Crowther M. Mortality outcomes in patients receiving direct oral anticoagulants: a systematic review and meta-analysis of randomized controlled trials. J Thromb Haemost. 2015;13(11):2012-20.

54. Kearon C, Akl EA, Ornelas J, et al. Antithrombotic Therapy for VTE Disease: CHEST Guideline and Expert Panel Report.
Chest. 2016;149(2):315-52.

55. Wang J, Cai C, Wang S. Merocel versus Nasopore for nasal packing: a meta-analysis of randomized controlled trials. Plosone. 2014;9(4):e93959.

56. Rimmer J, Lund VJ. Hereditary haemorrhagic telangiectasia. Rhinology. 2015;53(2):12934.

57. Hosman A, Westermann CJ, Snijder R, Disch $F$, Mummery $C L$, Mager JJ. Follow-up of Thalidomide treatment in patients with Hereditary Haemorrhagic Telangiectasia. Rhinology. 2015;53(4):340-4

\section{K M. Musgrave \\ Department of Haematology \\ Freeman Hospital \\ Newcastle Upon Tyne \\ United Kingdom, NE7 7DN}

Tel: 01912336161

E-mail:

Kathryn.musgrave@nuth.nhs.uk 